\title{
Street-connectedness and education in Kenya: Experiences of formal schooling as rationale for inclusive pedagogies of practice
}

\author{
Su Lyn Corcoran ${ }^{1} \cdot$ Lillian Aoko Awimbo $^{2}$ Kelvin Mugwanga ${ }^{3}$. \\ Irene Atieno Aluoch ${ }^{3}$
}

Published online: 20 August 2020

(C) The Author(s) 2020

\begin{abstract}
This article contributes to the literature on street-connectedness and inclusive education, presenting original research findings from two Kenyan studies. Both studies aim to understand street-connected young people's experiences of education. The first focused on transitioning from the street into education or training, to explore the challenges of making that transition. The second focused on young people who had lived on the street for extended periods of time and were still there at the time of data generation. Both studies generated significant insight into (a) education as motivating initial migrations to the street, (b) the role of fear, embarrassment, and shame in preventing young people from going (back) into formal education, and (c) how acceptance and support are key to overcoming feelings of not belonging and other challenges when transitioning from the street into school. The article provides empirical evidence that should be considered when planning inclusive education provision for street-connected young people globally.
\end{abstract}

Research projects involve many hands. We want to thank the following people for their support: Fred Achola, Hannah Cattermole, Margaret Eastcott, Vanessa Ingleson, Richard Fay, Vicky Ferguson, Anish Kurien, Kelly Lavender Smith, Adam Lovick, Emma McKinney, Susie Miles, Liz Mnengwah, Kate Pahl, Helen Pinnock, Dominic Seedall, Sam Sellar, Anthony Simpson, Yvette Solomon, Nayla Thompson, Joanna Wakia, and staff from the unnamed CSOs who assisted with Su's PhD.

Su Lyn Corcoran

su.corcoran@mmu.ac.uk

Lillian Aoko Awimbo

lawimbo2013@gmail.com

Kelvin Mugwanga

kevoad@gmail.com

Irene Atieno Aluoch

irinealuoch3@gmail.com

1 Education and Social Research Institute, Manchester Metropolitan University, Brooks Building, 53 Bonsall St, Hulme, Manchester M15 6GX, UK

2 Independent Researcher, Mombasa, Kenya

3 Glad's House Kenya, PO Box 93957 80100, Mombasa, Kenya 
Keywords Street-connected $\cdot$ Inclusion $\cdot$ Belonging $\cdot$ Kenya $\cdot$ Collaboration

International policy agendas, such as the Sustainable Development Goals (SDGs), prioritise universal access to quality education, positioning school as the place where children "belong" and education-heralded as improving outcomes and life changes—as a panacea for poverty (Kaneva and Corcoran 2020; Boyden 2015). However, while education has become globally applicable through international policy and legislation, such as the United Nations Convention for the Rights of the Child (CRC 2017), translating those ideals into practice is far less straightforward. What happens when formal schooling is the problem and young people, unable to "fit" the expectations reinforced by all aspects of their school environment, decide that the opportunities and benefits of being street-connected far outweigh the rewards that are perceived to be inherent to completing their education? What implications do the multiple deprivations and street-connectedness they experiencewhich should be reflected in policy that distinguishes them as street-connected, but which does not isolate them from other young people (Thomas de Benitez 2011) — have for how they transition (back) into schools?

Focusing on the social and educational justifications for inclusive education, defined in the broadest terms of equitable quality education for all learners, we discuss findings from two projects conducted with street-connected young people (SCYP) in Kenya. (In this article, young people refers to children under 18 years old and/or youth aged 18-28.) Drawing on SCYP's experiences of being street-connected and how they influence later transitions into education, we explore the challenges faced by young people in schools that motivated initial migrations to the street and/or prevented them from choosing to go (back) to school, as well as the challenges faced by those encouraged to leave the street for formal education settings. By focusing on young people's experiences, we aim to foreground the role of (not) belonging in shaping their pathways through education, and to problematise the power dynamics set up in schools (and societies) that lead to retention issues. Finally, we consider and position the experiences of SCYP within the broader discourse surrounding inclusive education.

\section{Locating street-connectedness}

SCYP are not a homogenous group and attempts to create a unified category are problematic. Civil society organisations (CSOs) working to support them may focus on the young people's situation as extremely vulnerable - at least to meet fundraising goals - and depict them as unable to support themselves and in need of our care and concern. On the other hand, SCYP are positioned as troublemakers or tools for political gain who need to be removed from the street (e.g., Wanzala and Adhiambo 2019). This rescue and/or removal binary fails to account for how socially, spatially, and even temporally complex SCYP's relationships and experiences are with the interactive space understood as the street (e.g., Aptekar and Stoecklin 2014; Beazley and Miller 2015; Lucchini 1999; Van Blerk 2005).

In trying to explain their lived realities, it is important to understand that SCYP's experiences are individual and describe a variety of potential opportunities and challenges (Kaneva and Corcoran, forthcoming; Street Invest 2014-2018). SCYP may live and/or work within this space full-time or part-time, engaging in street-based activities all day every day, regularly 
after school and/or during weekends and holidays, or infrequently. They may be street-connected with their parents (and/or to support their parents), be in regular contact with their families, or lack any parental interaction at all. SCYP may be street-connected in their hometowns or in completely different urban centres or countries from where they were born. They may be at risk of exploitation, abuse, and stigmatisation, but they may also be entrepreneurial and engaged in complex and innovative forms of livelihood generation.

It is possible to conceptualise street-connectedness, in all contexts, as identity-forming (e.g., Borg et al. 2012). A young person's experiences of being and becoming street-connected entail a fluid process of negotiation and renegotiation, as they navigate transient processes of figuring a sense of (not) belonging, both in relation to the physical space and the communities that reside within and beyond it (e.g., Beazley 2000; Corcoran 2016). SCYP exercise agency both in how they build their relationships and manage how the street monopolises their skills and energies. How they inhabit this space, and how they transform it into territory defined by their ownership of it, is influenced by the degree to which they exercise control over their own lives (Lucchini 1999).

If street-connectedness is identity-forming, both young people's reasons for being streetconnected and their experiences on the street are characterised by various processes, including neglect, cruelty, abandonment, financial opportunity, access to better nutrition, friendships and kinship ties, belonging to sub-cultures, and/or stigmatisation (e.g., Ayuku et al. 2004; Davies 2008; Wakia 2010). These factors influence their interactions with wider society both on the street, and for those that choose to make the transition, after they physically leave the street. For example, as Ferguson (2017) explained, the personas of strength and resilience constructed by some SCYP may be put into question if they admit to having little or no education, or if they cannot write their own name.

The right to education is firmly enshrined within the UN CRC, and the General Comment on Children in Street Situations (UNGC 21) provides definitive international directives for governments to tailor policy and support programmes for SCYP (United Nations 2017). However, while the general comment is a useful advocacy tool, encouraging governments to distinguish SCYP in policy, there is little research into how these rights are translated at the local level, or used to encourage collaboration between CSOs and local authorities for delivering context-appropriate interventions (Lucchini and Stoecklin 2020). While CSOs enable access to education for SCYP in a variety of ways (e.g., EENET 2017), does the formal education system, often positioned as the end point of the "reintegration journey", really provide inclusive spaces in which these young people can learn?

The findings discussed within this paper stem from two studies focused on SCYP in Kenya. While they do not address the mechanisms through which the right to education is enabled, they explore the experiences of young people with regards to education. The first study (Corcoran 2016), an ESRC-funded doctoral research project (grant code ES/J500094/1), explored young people's experiences of transitioning from the street into a variety of education and training placements, to understand the challenges they faced and, indirectly, the reasons why young people potentially drop out of education weeks, months, and sometimes years after they leave the street. The second study, funded by the British Academy (Grant code: SRG 170976), aimed to understand the education-related opinions and experiences of young people who had been street-connected for extended periods of time (Corcoran et al. 2020a). 


\section{Research design}

\section{The first study: Exploring transition experiences}

In the first study, Su conducted semi-structured interviews, auto-photography activities, and focus groups with 53 young people supported by three CSOs in two provincial towns, which were not named in the resulting thesis to ensure the participants' anonymity. These young people were attending various education and training placements, but they had all initially transitioned into primary or secondary schools after leaving the street. Kenya is currently rolling out a new competency-based curriculum, but all of the participants experienced the previous 8-4-4 education system taught in English: eight years of primary school and four each of secondary school and further education.

Using life history interviews (Goodson 2013) as a methodological starting point, the semi-structured interviews encouraged participants to think about their lives before they migrated to the street, their lives on the street, and their lives after they left the street. Follow-up questions, later data generation activities using drawings, auto-photography, and image elicitation interviews (Corcoran 2015a), and focus groups explored specific experiences of transitioning (back) into schools. CSO staff members joined the interviews to interpret from Kiswahili, Kikuyu, or Sheng (a creole mix of Kiswahili and other Kenyan languages used by young people; see Githiora 2002), and to provide support for the young people when sensitive issues arose during or after the interviews (Corcoran 2016). Care was taken to consider participants' expectations of the research and ensure that they understood the project and what their involvement entailed. The interviews were audio-recorded and later transcribed.

\section{The second study: Street-connected young people's opinions and experiences of education}

The first study helped clarify the issues faced by young people in education after leaving the street, but did not explore the experiences of those who had lived on the street for extended periods of time. In the second project, Kevin, Irene, and Lillian conducted data generation with 21 young people living and working on the street in Mombasa. This project was a collaboration with Glad's House (www.gladshouse.com), an organisation in Mombasa that works with SCYP. Su led a workshop on qualitative research methods for Glad's House social work and teaching teams. Kevin and Irene selected methods that could be integrated into the daily programmes of work and piloted the use of walking interviews (e.g., O'Neill and Roberts 2020), drawings, and image elicitation interviews within the social work and education programmes, to generate qualitative data for monitoring and evaluation. Research like this requires ethical approval from a recognised Kenyan research institution and a permit from the National Commission for Science, Technology, and Innovation (NACOSTI). Once our NACOSTI permit was issued, we invited 16 young people who had lived on the street for an extended period of time, or who were born on the street to street-connected parents, to participate. Lillian conducted focus group activities with six young men for whom she provided counselling support on a consultancy basis at Glad's House (Corcoran et al. 2020a).

Recruiting research participants from cohorts of young people who are already clients of a counsellor and/or supported by social work programmes raises ethical implications, particularly in terms of the client-practitioner relationship. Care was taken so the young 
people did not feel coerced to take part given our roles in supporting them and to ensure that they were able to give and withdraw informed consent. One participant withdrew halfway through the project. The participants chose not to be audio-recorded, so handwritten notes were made during or after data generation activities. Therefore, while direct quotes are provided for participant responses from the first study, we focus on the observations written in our research diaries for the second.

\section{Exploring street-connected young people's opinions and experiences of education}

In both studies, the data was analysed following an inductive bottom-up process (e.g., Braun and Clarke 2006), providing insights into how young people position and re-position themselves within street-based communities, schools, and wider society. In the first study, this process began with meetings between the researcher and the interpreters, at the end of each day of interviews, to discuss emerging themes and inform follow-up interviews. Later, the audio recordings and transcripts were repeatedly reviewed to further code the data (Corcoran 2016). In the second project, during initial analysis meetings the research team discussed notes made in research journals to identify emerging themes. These discussions continued asynchronously via WhatsApp and email over four months of data generation, locating existing themes in new participant responses as well as identifying new themes.

The participants form two groups: those who were born to street-connected parents and had always lived there participated in the second study in Mombasa, while those who had dropped out of education - for various reasons - and later migrated to the street participated in both studies. Negotiating a sense of belonging was a central theme for both groups. In relation to education, this concerned how acceptance and support helped young people fit in to new situations, but also with the effects of the shame and embarrassment associated with being street-connected. These themes translated into three key categories: the barriers to going (back) to school from the street, the issue of school being the reason for initial migrations to the street, and the challenges that young people face as they make the transition (back) to school.

\section{From street to school: Barriers to making the transition}

An inability to attend school is often cited as a reason for street-connectedness (e.g., Wakia 2010), often because parents cannot afford the resources needed and/or because young people are required to work to support their families financially. However, in Mombasa children do attend school at the same time as they are living on the street. Here, participants started school as small children but eventually left, either because they struggled to keep up with homework expectations or due to the financial burden of staying in school. Some dropped out because parents pressured them to spend more time on the street begging, but mainly they made the decision for themselves. The money earned brought immediate rewards, while the benefits promised for completing education were less tangible - especially when outreach programmes provided street populations with three meals a day and clothing. Since there were so many charitable individuals, churches, and businesses, positioning themselves as Good Samaritans, the money earned through begging and other street-based income-generating activities was used for other needs.

We know from our social work practice in Mombasa that mothers with young children can earn enough to cover their basic needs, especially given the access to various feeding programmes, but as their children grow their earnings decrease, encouraging them to have 
another baby to attract more sympathy. Consequently, as teenagers become more and more independent of their street-connected mothers, they find it increasingly difficult to earn enough. Three participants revealed how their career aspirations had involved wanting to become a teacher, train driver, and politician. However, as they came to realise the potential benefits of completing their education, they encountered additional barriers to going (back) to school. In Kenya, learners must return to the level of schooling they left, so 14-year-olds, for example, who did not finish Standard 2 (the second year of primary education), must attend classes with cohorts aged seven or eight years old, which may even include their younger siblings. It is difficult to admit to having received limited or no education, but for participants in both studies, being markedly different from classmates because of their advanced age, and knowing they would be at least 20 years old when they finished primary school in Standard 8, reinforced their embarrassment.

Additional self-esteem issues also affected participants' confidence about going to school. They highlighted difficulties fitting in to wider society, especially when labelled as chokora (a negative word for a street child). The stigmatisation they experienced influenced the belief that they would be a target for ridicule from teachers and peers. They also worried about not performing well academically, or simply having to sit down, concentrate, and remain focused on the teachers' lessons for any given length of time. They also feared the discipline meted out by teachers. Finally, the participants in Mombasa felt that belonging to street-based communities, which provided them with support and friendship, was too important to jeopardise. They disliked being labelled as weak by peers for talking to social workers, for example. Therefore, going (back) into education was not an easy decision.

\section{When school is the reason for migrating to the street}

A small number of participants from both studies $(n=9)$ mentioned problems with teachers as a reason why they dropped out of school and later migrated to the street. One described his relationship and arguments with a particular teacher that resulted in a temporary suspension from school and his decision to drop out completely. Though supported to go back into education, he was determined not to return, choosing vocational training instead. He wanted an income and to become self-reliant, seeing his future career as a way to find his place in society, be dependable, and able to assist others. In his words, "being a mechanic is good because if you know and you have that talent...you will see you are doing good and you will be able to help your family and you will be able to be learned and if you have a problem you can solve it". He was a model apprentice according to his mentor, had great aspirations, and was an intelligent and resourceful young man-potentially the most entrepreneurial of all of the participants across the two studies-but he had negative experiences of school.

A second young man's striking drawings revealed his experiences of school (Corcoran et al. 2020a). In the first drawing, a teacher stands at the chalkboard in front of students sitting in rows - representing that the teacher is in charge and thinks he knows what is best for the learners. In the second, the artist drew himself in a school uniform, kneeling on the ground holding two large stones aloft as two teachers look on. He was punished because he did not understand and complete the mathematics work set, and he subsequently dropped out. In the third image, he is drawn at the edge of the page looking towards a school building, a rucksack on his back. His explanation (translated from Kiswahili and written down during the interview): "I was very ambitious when I started school. I had hoped that I 
would be a very important person in this world. I always worked hard to be what I wanted - to drive a train - but I don't know what happened".

This talented young man regularly attended Glad's House street education programmes and could develop his artistic skills with support, but feared that he would be unable to live up to teachers' expectations if he went back to school. Other participants mentioned dropping out because completing homework was difficult without money for the oil needed for light, not to mention having little time after they completed their chores or worked to provide for their families. One found school boring and not as interesting as the opportunities and autonomy he had on the street. Staying at school, therefore, was either not meeting the needs of these young people or they were being actively made to feel that they did not belong in the classroom.

\section{The challenges of transitioning (back) into education}

When participants in the first study described their first days, weeks, or months at new schools, they highlighted several difficulties: getting used to the length of the school day, concentration, and routine $(n=8)$; learning to write $(n=2)$; meeting academic expectations $(n=5)$; using only English when they spoke other languages $(n=9)$; and adapting their behaviour and styles of learning accordingly $(n=11)$. The process of transitioning to new schools featured periods of upheaval as they refigured their place in relation to this new situation. All participants $(n=6)$ who were attending primary or secondary schools at the time of the first study, where they believed they were the only street-connected young person, kept aspects of their backgrounds private to be accepted in new schools. One invented a story about living with an aunt while his mother was sick to explain joining the school mid-year, and another chose to adopt his peers' misconception that his foster mother was his biological parent: "I have friends at my new school, but they do not understand. They take me as my good mother's child...I come from far and I am different... They do not understand me, and they do not know me".

Some participants could not reinvent themselves, especially after arriving on the first day in a vehicle with the CSO's "street child" logo. A head teacher introduced one young man to the student body by telling them to "look at this boy, he was a chokora and will give you all a challenge". Although he stressed the young man's academic ability, the teacher's introduction reflects a deficit attitude towards street-connectedness that prevented the student from being accepted immediately. His exam performance eventually afforded him status, respect, and friendship, and it increased self-confidence in his abilities and street-connected history. He acknowledged his time on the street as having "made [him] stronger".

Peer support was important to the process of settling in. One boy photographed the tree where he sat alone on his first day at school, because he "had no friend" (see also Corcoran 2015a). Another felt that all his previous learning had "left his head" and he could only advance when he made friends. The participants living in residential transitional care centres $(n=17)$ run by the CSOs, or in private boarding schools funded through donor-financed sponsorship $(n=11)$, had accessible support networks of young people who shared their experiences. However, access to such support groups meant being identifiable as part of that group: "if you tell someone your life story they cannot understand you. At [school] everyone knows [the organisation] so they know your life story".

Being "understood" implied support and acceptance, which this girl's peers at a private boarding school did not provide. They refused to work together or share books with academically able young people whose places were paid for by donors to the CSO: "sometimes I wish they did understand us better". The ten other sponsored students did not explicitly 
mention being accepted by the wider student body, but they all described their "friends" as being part of this group. In contrast, the children attending state-maintained primary schools local to the residential centres did not mention being unable to build friendships with peers outside of these centres, though there were complaints about the teachers.

Teachers' attitudes toward young people transitioning from the street and into their classrooms also influenced transition experiences, especially the welcome and support (or lack thereof) provided at new schools. One boy emphasised not even being shown where the toilets were at his primary school, and a second described being treated no differently to his classmates at another school on his first day when they were all caned for not submitting homework. He talked about the caning during an initial semi-structured interview, then reinforced its importance with a photograph of the tree where it happened for an autophotography exercise (see also Corcoran 2015a).

Teachers' acceptance and support was evident in the emotional and academic support provided and their perceived teaching skills. At the boarding school, one girl mentioned how the teachers "always attended the class", finished teaching the curriculum before the end of the year, and had positive attitudes towards the CSO-sponsored pupils, despite their not being accepted by their peers. As she put it, "Sometimes the teachers call us together to talk to us...we are brought together and counselled together. The head teacher, when you don't have anything you tell him, and he will produce for you. The teachers support you better". For her, being present, teaching effectively, and providing additional attention with regular meetings extended the notion of support with regards to learning.

Of course, the above examples are not representative of all participants' experiences at new schools. Eight participants who were still living in residential centres in the first study referred only to their happiness at being (back) at school. However, the majority of the participants in this study described varying levels of support and acceptance from their teachers, friends, and school-based peers.

\section{Street-connectedness and education: A complex relationship}

Exploring the findings from these two Kenya-based studies highlights a) the role of education in motivating initial migrations to the street, b) the role of fear, embarrassment, and shame in preventing young people from going (back) into formal education, and c) how acceptance and support are key to overcoming feelings of not belonging and the challenges faced by SCYP transitioning into schools.

SCYP's negative experiences of formal schooling, and how they influence decisions to drop out and later migrate to the street, are represented by the young men who argued with teachers or were punished for not understanding lessons. Other participants described being bored, unable to keep up with assigned work (especially homework), difficulty working in English when they spoke other languages at home, and struggling to meet teachers' expectations in terms of discipline and performance. However, while many organizations that work with SCYP focus on access to education, there is limited research into SCYP's experiences of school. One study in Western Kenya (Taylor et al. 2019) explored education provision through an intersectional lens of street-connectedness and disability, focusing on SCYP assessed as also having communication disabilities. Taylor and colleagues described these disabilities as expressive language disorders resulting from neglect, trauma, cruelty, abandonment. They also related them to language barriers arising from the participants' predominant use of their mother tongue or Sheng, which was also an issue for three of the 
participants in our first study. Because they are often hidden disabilities, communication disabilities can go unrecognised or unacknowledged, and Taylor and colleagues' participants struggled to navigate "hostile" school environments and frequent bullying by students and teachers.

Similar environments exist for young people who identify as having been streetconnected, whether or not they also identify as having a disability or language issues. The general public's negative and stigmatising attitudes toward street-connectedness, described by participants in both studies presented in this paper, was evident in the schools. For example: the head teacher's surprise and fellow students' initial disbelief at an academically able chokora; participants in the boarding school struggling to fit in when everyone knew their history; and the young men who re-wrote their back stories when they joined new schools. Street-connectedness was equated to inability and/ or being a troublemaker. Such deficit attitudes towards SCYP, also described by Corcoran (2015b) and Dladha and Ogina (2018), have the potential to instil feelings of inadequacy and shame that influence decisions to drop out of school (again), as well as preventing later returns to education. The participants not in school in Mombasa, worried about not performing well academically if they went (back) to school and about their peers' negative attitudes towards street-based lives - and their embarrassment increased at the notion of joining classes with much younger peers after being out-of-school for extended periods of time.

SCYP can develop social and emotional attachments to the street, finding belonging, social capital and support through the bonds they share with each other and the sub-cultures they co-construct, often in direct opposition to their treatment by members of the public (e.g., Beazley 2003: Davies 2008). The upheaval of leaving can therefore produce positive feelings like hope and self-confidence, but also "loneliness, guilt, and disloyalty" that are difficult to overcome when trying to disengage (Karabanow 2008, p. 782). Multiple deprivations experienced over time, alongside their street-connectedness, impact both their relationship with the street and their relative wellbeing (Corcoran and Wakia 2013; Thomas de Benitez 2011). In turn, this affects the identity they figure for themselves and their feelings of (not) belonging — or identities of exclusion (Karabanow 2008) — in other situations.

Research focusing on "looked after" children moving between schools in the UK (Brewin and Statham 2011) or on children with disabilities moving between levels of the education system in Armenia (Bridge of Hope 2015) showed that students' experiences of settling in to a new school affect their relative levels of wellbeing. In lieu of limited research from countries similar to Kenya, both of these studies highlight the importance of holistic approaches to transitions, specific to the needs of the individual, that are scaffolded in positive relationships among parents, teachers, and students. Taylor et al. (2019) suggest that "experience and familiarity" can change negative and deficit attitudes, which is evident in the responses of the young man introduced to the whole school as chokora. Although his academic ability influenced his popularity, in time he overcame this negative stereotype to build friendships.

In attempting to negotiate their transition into schools, especially within societies that uphold negative views about street-connectedness, the participants emphasised that welcoming learning environments, acceptance and support from teachers, and friendship and peer support are integral to the process. There is therefore a need to think beyond access to education and getting children into school, to consider long-term strategies that provide effective support systems (Djone and Suryani 2019). Such frameworks require building trusting relationships between SCYP and social work teams, building self-confidence 
and well-being through effective reintegration programmes that strengthen connections with family, school, and the community (Corcoran and Wakia 2013; Kaime-Atterhög et al. 2007; Volpi 2002), and advocating for the provision of further support systems. Van Raemdonck and Seedat-Khan (2018) in South Africa reviewed mentorship programmes for young people transitioning into school, evaluating mentorship provided by social work teams as well as peers who have already undertaken the transition. Although successful, such programmes rely on financial investment and changes to education policy and practice agendas.

Developing inclusive pedagogies of practice takes time (Lewis et al. 2019), and collaboration, especially between schools, is an important first step to building effective schools and school systems to tackle wider inequalities and enable inclusive, quality education (Ainscow et al. 2012). Given the wealth of experience that CSOs working with SCYP have in providing access to learning (e.g., EENET 2017), such collaborations should also involve a cross-sectoral representation of stakeholders from these organisations, working with teachers to develop effective systems of support. Collaborative approaches can advocate for different groups of learners (such as SCYP, refugees, or children with hidden disabilities), highlighting the diversity that exists within the student cohort, challenging deficit conceptualisations, and developing teachers' understanding of their students and their associated needs, to encourage learning and minimise barriers to learners' developing a sense of belonging. At the local level, the development of inclusive pedagogies of practice could start with collaboration between educators working on education programmes at streetbased drop in centres - for example, collaborating with teachers in schools to adapt catchup curricula and after school club activities-as well as forming effective partnerships for sharing good practice and supporting effective transitions (Moore 2017; Thomas de Benitez 2013). These partnerships could be extended to networks of schools and CSOs, in collaboration with local education officers, taking bottom-up, "beyond schools" approaches (Ainscow 2020) to addressing the social and economic processes that affect SCYP and their access to and retention in education.

It is not possible to provide a definitive position on whether SCYP should be identified to teachers when they start at a new school. The participants at the boarding school had the support of peers with similar experiences, but those attending schools local to their family homes, especially in rural areas, could not fall back upon these networks if they were not accepted by the wider school community. "Familial isolation" (Sherry 2004) has been used to describe how it feels to be the only person in a household who has lived on the street (Corcoran 2015b), which can be exacerbated by trying to fit traditional expectations of behaviour at home after one's experiences of street-based autonomy (Beazley 2000). This isolation extends to feelings of being the only street-connected young person in a school.

In addition to the multiple deprivations associated with a young person's street-connectedness (Thomas de Benitez 2011), they may also be at the intersection of multiple categories of need associated with gender, disability, HIV, forced displacement, etc. (Corcoran et al. 2020b; Ward and Seager 2010). There is therefore a danger to taking a siloed approach to inclusion in education, where only one category of need is prioritised or funded, or where young people are segregated into alternative education provision because of a perceived deficit in their ability to learn (Miles and Singal 2010). A South African study exploring "developmental delay" and additional social and emotional challenges faced by SCYP suggested that some of their participants were unable to cope with the demands of mainstream schools (Van Jaarsveld et al. 2011). However, such a position could lead to all SCYP being excluded, especially when the diversity in their population is not recognised and policies for alternative education provision specifically name them 
(Corcoran 2015b). As Pather (2011) showed, learners with a range of abilities can be included successfully in mainstream settings, even when there are few resources (Stubbs 2008).

Therefore, it is important for teachers to develop an understanding of what it means to be street-connected, but alongside (re)training of the idea that the average child does not exist-every learner brings their own particular backstory and combination of needs to the classroom that they may or may not wish to share. Given that the participants highlighted both positive and negative implications of identifying themselves as having been streetconnected, acknowledging (but not necessarily identifying) the potential experiences of individuals within the student body may be an important first step towards change. Developing inclusive pedagogies of practice that scaffold learning from where each student finds themselves to be and considering their individual learning needs-providing a twin-track approach to inclusion when special attention is required (Bouille 2013) — could also reduce the likelihood of negative school experiences and prevent young people from dropping out and migrating to the street. Although there did not appear to be a programme explicitly challenging student prejudice directed towards CSO-supported students at the boarding school, teachers set up a system of regular meetings and support, alongside the academic programme, for those who were sponsored by the CSO. Effective inclusive practice in schools starts with a process of listening to learners (Ainscow and Messiou 2018) and from there identifying and challenging the limiting assumptions that teachers have about the young people in their classes. A next step at the boarding school would be to build in work with the wider student body to help them "understand" the young people receiving sponsorship.

For some young people, the street is a space characterised by trauma and violence, but there are also SCYP who run from traumatic experiences at home (Thomas de Benitez 2007), making the street a relatively safer space. The role of CSOs is therefore important as well as difficult. These organisations provide young people with support and opportunities to leave the street, but the development of trusting relationships between SCYP and staff members is difficult when adults have repeatedly let them down (Ferguson 2017). The regular meetings at the boarding school extend this approach as teachers pick up on the work started by the social work team: building trust and forging appropriate relationships between adults and young people previously let down by adults. This system of meetings could be expanded to support and benefit all learners and, in acknowledging and responding to individual differences, change deficit attitudes and potentially prevent young people from dropping out of school because of negative experiences.

In order to define and deliver appropriate support for young people, they must be part of that process (Johnson 2017). They are agents who are capable of affecting change in their own situations - especially when they are enabled and encouraged to do so. Lucchini (1993) described two main competencies developed by SCYP. Instrumental competency refers to the visibly observable attributes of skills, knowledge, and abilities engaged in activities like income-generation that young people develop during their time on the street. Symbolic competencies, on the other hand, are invisible and refer to their abilities to form useful friendships and engage problem-solving capabilities, to ensure survival on the street. SCYP's experiences and capabilities, and the levels of autonomy and skills building they have developed in order to survive on the street, are therefore just as important to the decisions made about their education and wider service provision. Interventions should be culturally responsive, young person-centred, and where possible, young personled (Ferguson 2017). Moore (2017), for instance, in an article about a democratic school 
educating street-connected young people in the Philippines, noted that when young people are included and invested in a school's decision-making process, engagement and retention improve.

Older SCYP, who feel unable to return to mainstream primary schools, or even to start school for the first time at an advanced age, may need additional support as they return to classrooms. In Kenya, public school is the only free education available for students under the age of 18. Free vocational training is available after age 18, but younger students who wish to access alternative education provision must pay to do so privately. Ensuring that young people leaving the street achieve a minimum level of basic education in line with the SDGs-giving them a foothold in an increasingly competitive labour marketmay require providing alternative pathways to achieving formal education (basic literacy, numeracy, and/or end of Primary/Secondary school certification) in the short term. Three of the four CSOs in this paper deliver catch-up curricula at drop-in centres, scheduled to fit around young people's work on the street, or at their residential centres. These programmes aim to support young people through the transition away from the street and (back) into schools (Yohannes et al. 2017). However, such accelerated programmes of learning can also be effective in helping young people skip a year or two of school (Moore 2017). Some young people supported by the CSOs do choose to go back to school at an advanced age and eventually achieve their Kenya Certificate of Secondary education, but others prefer to choose different education pathways, potentially also continuing their basic education at the CSO centres and registering for national examinations as private candidates.

\section{Conclusions}

Both studies demonstrate that there is no one way of working that fits each individual. For example, there were positive and negative aspects to taking groups of street-connected children to the same primary school and to enabling them to attend a school on their own. However, recommendations are possible for support programmes offered by organisations and/or education centres. CSOs working with SCYP have found that those who are (forcibly) removed from the street by police and municipal authorities are much more likely to drop back to the street than remain in residential centres or family homes (Corcoran and Wakia 2013; Kaime-Atterhög and Ahlberg 2008). Each individual migrates to the street because of a specific combination of motivating factors (Wakia 2010), and experiences life on the street in their own individual way. Leaving the street is therefore an ongoing process that starts when a young person is able to visualise a life trajectory for themselves beyond the street (Lucchini 1999); it is successful when they feel listened to, respected, and understood (Kaime-Atterhög and Ahlberg 2008). These young people must therefore make active decisions to leave the street, if they choose to do so at all, and exercise a degree of agency over the process, as they move (back) into family homes or alternative care situations and, later, into schools. Support is needed during this transition period, in addition to time spent in a non-formal education setting, such as Glad's House education programmes, as they prepare to go back into formal classrooms.

In one sense, then, SCYP do not leave the street (Corcoran 2016). They may be physically removed from the space, but their experiences of leaving and continuing through education suggest that street-connectedness is not spatially or temporally constrained. Rather, it is a process of becoming and making sense of the self within the context of the street. 
Likewise, leaving the street is another process of becoming in which street-connected identities continue to be constructed and re-constructed. As individuals transition into new communities, they figure a sense of belonging in relation to their experiences of the transition and the interactions they have with others in that community. They are therefore able to settle into schools better when they feel supported and accepted, influencing long-term aspects such as academic performance or the roles that they envision for themselves at home and in society.

Open Access This article is licensed under a Creative Commons Attribution 4.0 International License, which permits use, sharing, adaptation, distribution and reproduction in any medium or format, as long as you give appropriate credit to the original author(s) and the source, provide a link to the Creative Commons licence, and indicate if changes were made. The images or other third party material in this article are included in the article's Creative Commons licence, unless indicated otherwise in a credit line to the material. If material is not included in the article's Creative Commons licence and your intended use is not permitted by statutory regulation or exceeds the permitted use, you will need to obtain permission directly from the copyright holder. To view a copy of this licence, visit http://creativecommons.org/licenses/by/4.0/.

\section{References}

Ainscow, M. (2020). Promoting inclusion and equity in education: Lessons from international experiences. Nordic Journal of Studies in Educational Policy, 6(1), 7-16.

Ainscow, M., Dyson, A., Goldrick, S., \& West, M. (2012). Making schools effective for all: Rethinking the task. School Leadership \& Management, 32(3), 197-213.

Ainscow, M., \& Messiou, K. (2018). Engaging with the views of students to promote inclusion in education. Journal of Educational Change, 19, 1-17.

Aptekar, L., \& Stoecklin, D. (2014). Street children and homeless youth: A cross-cultural perspective. Chem: Springer.

Ayuku, D., Kaplan, C., Baars, H., \& De Vries, M. (2004). Networks and personal social networks of the on-the-street, of-the-street, shelter and school children in Eldoret, Kenya. International Social Work, 47(3), 293-311.

Beazley, H. (2000). Street boys in Yogyakarta: Social and spatial exclusion in the public spaces of the city. In S. Watson \& G. Bridges (Eds.), Companion to the city (pp. 472-488). London: Blackwell.

Beazley, H. (2003). Voices from the margins: Street children's subcultures in Indonesia. Children's Geographies, 1(2), 181-200.

Beazley, H., \& Miller, M. (2015). The art of not being governed: Street children and youth in Siem Reap, Cambodia. Politics, Citizenship and Rights, 7(1), 263-289.

Borg, L., Thompstone, G., Thomas de Benitez, S., \& Bell, B. (2012). Child protection systems: Challenges and opportunities for addressing specific issues faced by children. Discussion paper prepared for the global conference on Protecting children better: Theory and practice of child protection systems. New Delhi, India, November 13-16.

Bouille, S. (2013). Developing an itinerant teacher system that supports a twin-track approach to inclusive education, Cambodia. Enabling Education Review, 2, 12-13.

Boyden, J. (2015). Childhood and the policy makers: A comparative perspective on the globalisation of childhood. In A. James \& A. Prout (Eds.), Constructing and Reconstructing Childhood Contemporary issues in the sociological study of childhood (pp. 167-201). Abingdon: Routledge.

Braun, V., \& Clarke, V. (2006). Using thematic analysis in psychology. Qualitative Research in Psychology, 3(2), 77-101.

Brewin, M., \& Statham, J. (2011). Supporting the transition from primary school to secondary school for children who are looked after. Educational Psychology in Practice: Theory, Research and Practice in Educational Psychology, 27(4), 365-381.

Bridge of Hope (2015) Education transition for children with disabilities in Armenia. Research report. EENET and Open Society Foundations. https://www.eenet.org.uk/resources/docs/Armenia_transition _research_FINALd.pdf. 
Corcoran, S. (2015a). Visualising transitions: The use of auto-photography with formerly street-connected boys in Kenya. In S. Miles \& A. Howes (Eds.), Photography in educational research: Critical reflections from diverse contexts (pp. 168-181). London: Routledge.

Corcoran, S. (2015b). Disabling streets or disabling education? Challenging a deficit model of street-connectedness. Disability and the Global South, 2(2), 613-619.

Corcoran, S. (2016). Leaving the street? Exploring transition experiences of street-connected children and youth in Kenya. Doctoral dissertation. Manchester: University of Manchester.

Corcoran, S., Awimbo Mugwanga, K., Aluoch, I., \& Mnengwa Achola, L. (2020a). (Re-)engaging streetconnected youth with education in Mombasa, Kenya. Manchester: Glad's House and Manchester Metropolitan University.

Corcoran, S., Atukunda, C., Ferguson, F., Moliere, F., Pahl, K., Tallio, V., et al. (2020b). Belonging and learning: Using co-produced arts methodologies to explore youth participation in contexts of conflict in Kenya. Uganda and the Democratic Republic of Congo (DRC): Manchester Metropolitan University.

Corcoran, S., \& Wakia, J. (2013). Evaluating outcomes: Retrak's use of the Child Status Index to measure wellbeing of street-connected children. Manchester: Retrak.

CRC [United Nations Committee on the Rights of the Child] (2017). General comment no. 21 (2017) on children in street situations. https://www.streetchildren.org/resources/generalcomment-no-21-2017-onchildren-in-street-situations/.

Davies, M. (2008). A childish culture? Shared understandings, agency and intervention: An anthropological study of street children in northwest Kenya. Childhood, 15(3), 309-330.

Dladha, J., \& Ogina, T. (2018). Teachers' perceptions of learners who are street children: A South African case study. South African Journal of Education, 38(1), S1-S8.

Djone, R., \& Suryani, A. (2019). Child workers and inclusive education in Indonesia. The International Education Journal: Comparative Perspectives, 18(1), 48-65.

EENET [Enabling Education Network] (2017). Enabling education review 6: Street-connected young people and inclusive education. Hyde: Enabling Education Network.

Ferguson, V. (2017). Enabling education for long-term street-connected young people in Kenya. Enabling Education Review, 6, 45-47.

Githiora, C. (2002). Sheng: Peer language, Swahili dialect or emerging Creole? Journal of African Cultural Studies, 15(2), 159-181.

Goodson, I. (2013). Developing narrative theory. Abingdon: Routledge.

Kaneva, D., \& Corcoran, S. (2020). Homeless and/or street connected childhoods: Contemporary challenges with an international convention frameworks. In M. Perez, M. Tesar, N. Yelland, N. Fairchild, \& L. Peters (Eds.), The SAGE handbook of global childhoods. London: SAGE.

Kaime-Atterhög, W., \& Ahlberg, B. (2008). Are street children beyond rehabilitation? Understanding the life situation of street boys through ethnographic methods in Nakuru, Kenya. Children and Youth Services Review, 30, 1345-1354.

Kaime-Atterhög, W., Lindmark, W., Persson, L.-A., \& Maina Ahlberg, B. (2007). Burning "Centre Bolt": Experiences of sexually transmitted infections and health care seeking behaviour described by street boys in urban Kenya. Children and Youth Services Review, 29, 600-617.

Karabanow, J. (2008). Getting off the street: Exploring the processes of young people's street exits. American Behavioral Scientist, 51(6), 772-788.

Johnson, V. (2017). Moving beyond voice in children and young people's participation. Action Research, 15(1), 104-124.

Lewis, I., Corcoran, S., Juma, S., Kaplan, I., Little, D., \& Pinnock, H. (2019). Time to stop polishing the brass on the Titanic: Moving beyond 'quick-and-dirty' teacher education for inclusion, towards sustainable theories of change. International Journal of Inclusive Education, 23(7-8), 722-739.

Lucchini, R. (1993). Street children: A complex reality. Working paper 224. Fribourg: Institute for Economic and Social Sciences, University of Fribourg.

Lucchini, R. (1999). L'enfant de la rue: Carrière, identité et sortie de la rue. Fribourg: Université de Fribourg.

Lucchini, R., \& Stoecklin, D. (2020). Children in street situations. New York: Springer.

Miles, S., \& Singal, N. (2010). The Education for All and inclusive education debate: Conflict, contradiction or opportunity? International Journal of Inclusive Education, 14(1), 1-15.

Moore, R. (2017). Democratic education in the Philippines: What happens when students and teachers run the school together? Enabling Education Review, 6, 7-9.

O’Neill, M., \& Roberts, B. (2020). Walking methods: Research on the move. London: Routledge.

Pather, S. (2011). Evidence on inclusion and support for learners with disabilities in mainstream schools in South Africa: Off the policy radar? International Journal of Inclusive Education, 15(10), 1103-1117. 
Sherry, M. (2004). Overlaps and contradictions between queer theory and disability studies. Disability \& Society, 19(7), 769-783.

Street Invest (2014-2018). Growing up on the streets. Briefing papers 1-14. https://www.streetinve st.org/resources/growing-streets.

Stubbs, S. (2008). Inclusive education: Where there are few resources. Oslo: Atlas Alliance.

Taylor, C., Sotiropoulou Drosopoulou, C., Rochus, D., \& Marshall, J. (2019). Street-connected children with communication disabilities and their caregivers in Western Kenya: Experiences, beliefs and needs. Disability and Rehabilitation. https://doi.org/10.1080/09638288.2019.1699174.

Thomas De Benitez, S. (2007). State of the world's street children: Violence. London: Consortium for Street Children.

Thomas De Benitez, S. (2011). State of the world's street children: Research. London: Consortium for Street Children.

Thomas De Benitez, S. (2013). A participatory assessment of street to school programmes: Global report. London: AVIVA.

Van Blerk, L. (2005). Negotiating spatial identities: Mobile perspectives on street life in Uganda. Children's Geographies, 3(1), 5-21.

Van Jaarsveld, A., Vermaak, M., \& van Rooyen, C. (2011). The developmental status of street children in Potchefstroom, South Africa. South African Journal of Occupation Therapy, 41(1), 1-5.

Van Raemdonck, L., \& Seedat-Khan, M. (2018). A case study on a generalist service delivery model for street children in Durban, South Africa: Insights from the capability approach. Child \& Family Social Work, 23, 297-306.

Volpi, E. (2002) Street children: Promising practices and approaches. Working Paper 26388. Washington, DC: World Bank Institute.

Wakia, J. (2010). Why are children on the streets?. Manchester: Retrak.

Wanzala, J., \& Adhiambo, M. (2019). Street children: The problem that refuses to go away despite funding. https://www.standardmedia.co.ke/article/2001342774/street-families-future-bleak-as-rehabilitationflops-and-numbers-rise.

Ward, C., \& Seager, J. (2010). South African street children: A survey and recommendations for services. Development Southern Africa, 27(1), 85-101.

Yohannes, B., Sintayehu, B., Alebachew, Y., \& Kay, L. (2017). Catch-up education: The door to future possibilities in Ethiopia. Enabling Education Review, 6, 20-21.

Publisher's Note Springer Nature remains neutral with regard to jurisdictional claims in published maps and institutional affiliations.

Su Lyn Corcoran is a researcher at the Education and Social Science Research Institute, Manchester Metropolitan University, and a programme officer at the Enabling Education Network, where she co-edits the Enabling Education Review. She draws on her experience of teaching science and theory of knowledge in the UK and the international sector, and of working with international non-governmental organisations delivering programmes in lower income countries, to take a cross-sectoral and interdisciplinary approach to research. Su is interested in "blue sky inclusion" (inclusive education in the broadest sense), refugees, streetconnectedness, equity in education, youth employment and social justice. Her research is mainly focused on East and Central Africa.

Lillian Aoko Awimbo completed her doctorate in counseling studies in 2016, as part of a collaborative program delivered by the Kenya Association of Professional Counsellors (KAPC) and the University of Manchester. She has been a practicing counsellor for 20 years and has been providing her services to streetconnected children supported by Glad's House for 5 years. Lillian is interested in non-directive play therapy, particularly its development for counselling practice with children and young people in the context of Kenya.

Kelvin Mugwanga has worked for Glad's House for over five years as a social worker supporting streetconnected children and youth in Mombasa, Kenya. He has a diploma in community development and social work and specialises in child protection and safeguarding. Kelvin has ethnographic research experience, developed in line with Street Invest's monitoring and evaluation initiatives, and has used multiple qualitative data generation methods as a result of a second partnership with Manchester Metropolitan University, focused on young people's opinions and experiences of education. 
Irene Atieno Aluoch is a street worker at Glad's house. She has a diploma in community development and counselling and over two years' work experience with street-connected children. Irene works in the Glad's House street education programme, delivering non-formal education at various street-based locations in Mombasa, Kenya. She has been developing her research experience as part of partnerships with Street Invest and Manchester Metropolitan University and is looking at developing an education programme in line with young people's expectations. 